\title{
Law of Distribution of Quantities of Shells on Togolese Littoral
}

\author{
Kossi Bollanigni Amey ${ }^{1,2}$ \\ ${ }^{1}$ Ecole Nationale Supérieure d'Ingénieurs de l'Université de Lomé, Lomé, Togo \\ ${ }^{2}$ Equipe de Recherche et Développement de FORMATEC, Lomé, Togo \\ Email: ameykoss3@yahoo.fr
}

How to cite this paper: Amey, K.B. (2020) Law of Distribution of Quantities of Shells on Togolese Littoral. Open Journal of Civil Engineering, 10, 69-82.

https://doi.org/10.4236/ojce.2020.101007

Received: February 25, 2020

Accepted: March 23, 2020

Published: March 26, 2020

Copyright (c) 2020 by author(s) and Scientific Research Publishing Inc. This work is licensed under the Creative Commons Attribution International License (CC BY 4.0).

http://creativecommons.org/licenses/by/4.0/

\begin{abstract}
This study aims at analyzing the repartition of the quantities of shells of sand sediments of Togolese littoral, and at determining the law underlying their longitudinal and transversal distributions. Samples (210), collected all along Togolese littoral starting from Togo-Ghana border up to Togo-Benin border, are subject to the test of sieving. Each refusal on sieve is tested against construction of shells by hydrochloric acid. The determination of the quantity of shells according to their size and to longitudinal and transversal distributions on the littoral is completed. As a conclusion, the quantity of shells in the sediments is getting lower and lower starting from the aerial mid-beach (14.2\%) to the mid-foreshore $(11.80 \%)$, and getting higher and higher from the mid-foreshore (11.80\%) to the low-foreshore (13.32\%). It is getting lower and lower according to the direction of sediments' transportations. This quantity of shells is high $(40.87 \%)$ in the fine-grained sands $(\phi<0.125 \mathrm{~mm})$ and coarse-grained sands $(\phi>2 \mathrm{~mm})$ and low $(>24.26 \%)$ in the average-grained sands $(0.125 \mathrm{~mm} \leq \phi \leq 2 \mathrm{~mm})$. The average quantity of shells of $12.67 \%$ is lower than the recommended maximum quantity (30\%) for the sands used for concrete. Thus, for the concrete works, the littoral sands might be seen as useful since they are granulating for concrete.
\end{abstract}

\section{Keywords}

Sediment, Togolese Littoral, Quantity of Shells, Distribution

\section{Introduction}

Most of the works of civil engineering completed in Togo are in concrete which is a composite material mostly made up of granulates, binder and water. The choice of the size of granulates depends on expected results for concrete (desired 
property). Water-resistant and permeable concrete are, among other things, researched properties for a concrete. One of fundamental parameters which influence the physical aspect of concrete is the cleanness of granulates [1].

Different kinds of sands are used in Togo as granulates. These are sea sands, river sands, sands from rock crashing and continental dunes [2] [3].

In order to meet the demand for sands for construction projects in Lomé and in the littoral areas in Togo, the littoral sands are always used, which contain shells of animal as shellfish (ocypodidae), and mollusks (aplacophores, bivalves, cephalopods and brachiopods) [4].

These shells are classified into three groups according to their surface and duration. We distinguish then [4]:

- Shells with rough and hard surfaces: ringens, arca senelis, cardium costatam, littorina puntata, donax rugorus, venus verrucasa, phyllonotus pomum, bolinus brandaris, murex küensis, etc.

- Shells with hard and smooth surfaces: chinas, Cônes and Nautidus.

- Shells that go rotten in the soil at a certain depth after some time: all the shellfishes and cuttlefishes.

The shells are made up of calcium that is decayed by chemical agents, which is detrimental to concretes that may be porous and even weaken their resistances.

The determination of the quantities of sand sediments is sought through the samples collected all along the Togolese littoral over $50 \mathrm{~km}$ from the border with Ghana (PK0) up to the border with Benin (PK 50) in view of searching for the distribution of quantities of shells according to longitudinal and transversal profiles and according to their differential distribution. This study will allow assessing how possible it is to use the sea granulates in the constructions.

\section{Material and Method}

\subsection{Material}

Collections of samples of sediments are carried out over thirty-five (35) profiles from the border Togo-Ghana up to the border Togo-Benin over a distance of 50 $\mathrm{km}$ (Figure 1 and Table 1). On each of profiles, sediments are taken on the low-foreshore (Bas-E), the mid-foreshore (Mi-E), the high-foreshore (Haut-E) and on the aerial beach at $5 \mathrm{~m}$ from high-foreshore (Début-PA), $10 \mathrm{~m}$ from high-foreshore (Mi-PA), and at the end of the aerial beach (Fin-PA) as shown on Figure 2. In addition to sand sediments, hydrochloric acid is used for destroying shells.

\subsection{Method}

The collected sands are dried up in a steamroom at $105^{\circ} \mathrm{C}$ during 20 hours. The dried samples are then subjected to a sieving test on sieves with meshes of $0.08 \mathrm{~mm}-0.125 \mathrm{~mm}-0.25 \mathrm{~mm}-0.5 \mathrm{~mm}-1 \mathrm{~mm}-2 \mathrm{~mm}-4 \mathrm{~mm}$ and $5 \mathrm{~mm}$ [5]-[11]. 
Table 1. Positions of different profiles [3].

\begin{tabular}{cccccccccccccccccccc}
\hline Profiles & 1 & 2 & 3 & 4 & 5 & 6 & 7 & 8 & 9 & 10 & 11 & 12 & 13 & 14 & 15 & 16 & 17 & 18 \\
\hline Distance: PK $(\mathrm{km})$ & 0 & 2 & 4 & 5 & 6 & 7 & 8 & 9 & 10 & 12 & 16 & 18 & 20 & 24 & 28 & 29 & 30 & 32 \\
$\quad$ Profil & 19 & 20 & 21 & 22 & 23 & 24 & 25 & 26 & 27 & 28 & 29 & 30 & 31 & 32 & 33 & 34 & 35 & \\
Distance: PK $(\mathrm{km})$ & 34 & 35 & 36 & 37 & 38 & 39 & 40 & 41 & 42 & 43 & 44 & 45 & 46 & 47 & 48 & 49 & 50 & \\
\hline
\end{tabular}

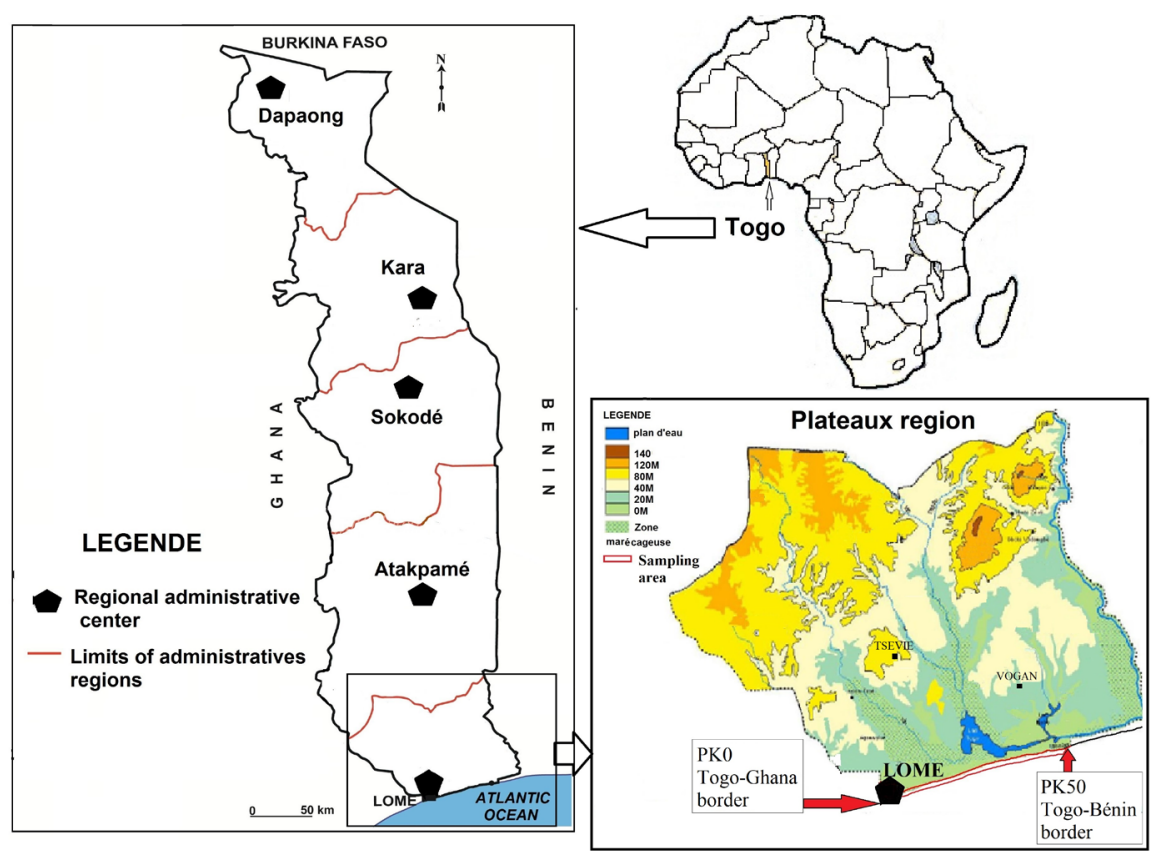

Figure 1. Location of samples collection area [3].

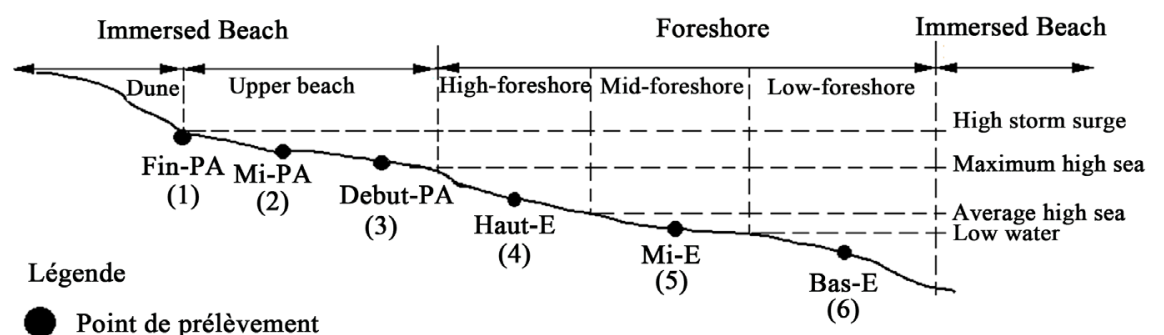

Figure 2. Profile across the beach indicating the location of sample collection.

The tests are performed in civil engineering laboratories of National Higher School of Engineers (ENSI) at the University of Lomé (UL) and at the FORMATEC Institute in Togo.

The determination of quantities of shells is performed in three stages.

Stage 1: Search for the relationship between the quantity of shells and the total mass of the sand

In submitting the shells to a hydrochloric acid test, chemical reactions arise leading to their destruction. The chemical formula of reactions is given by:

$$
\mathrm{CaCO}_{3}+2 \mathrm{HCl} \rightarrow \mathrm{CaCl}_{2}+\mathrm{CO}_{2}+\mathrm{H}_{2} \mathrm{O}
$$


With:

$\mathrm{CaCO}_{3}$ : Calcium carbonate (which is, in our case, the shells)

HCl: Hydrochloric acid

$\mathrm{CaCl}_{2}$ : Sodium chloride

$\mathrm{CO}_{2}$ : Carbone dioxide

$\mathrm{H}_{2} \mathrm{O}$ : Water

Since the sands of littorals consist of shells, the determination of the quantity of shells is carried out through destruction by means of hydrochloric acid. Thus, in order to establish a law between the reduction of the initial mass of sand after reaction $(\Delta m)$ and the quantity of shells $\left(m_{c}\right)$ having reacted to the hydrochloric acid, samples of masses of $1 \mathrm{~g}$ of shells are submitted to destruction tests in the hydrochloric acid. Either the Formula (2), the law between $\Delta m$ and $m_{c}$.

$$
\Delta m=f\left(m_{c}\right)
$$

\section{Stage 2: Tests of destruction of shells of sediments}

Each refusal on sieve $(0.08 \mathrm{~mm}-0.125 \mathrm{~mm}-0.25 \mathrm{~mm}-0.5 \mathrm{~mm}-1 \mathrm{~mm}-2$ $\mathrm{mm}-4 \mathrm{~mm}$ and $5 \mathrm{~mm}$ ) caused by sieving of 210 samples of sand sediments, is submitted to the destruction test of shells by the following procedure:

- Introduction of hydrochloric acid of mass ma;

- Introduction of raw sand of mass $\mathrm{mb}$ in the solution $\mathrm{HCl}$;

- Weighing of the final solution after reaction, given $m_{f}$ the mass obtained.

\section{Stage 3: Calculation of the content of shells}

Supposing that the silica doesn't react at the contact with hydrochloric acid, the chemical reaction of destruction of shells in the sand is given by the chemical Formula (3).

$$
\mathrm{Si}_{2}+\mathrm{CaCO}_{3}+2 \mathrm{HCl} \rightarrow \mathrm{CaCl}_{2}+\mathrm{CO}_{2}+\mathrm{H}_{2} \mathrm{O}+\mathrm{Si}_{2}
$$

With Si, silica.

Supposing also that the sea sediments from Togolese littoral are made up only of silica and shells, and in designating by $m_{s}$ the mass of the silica, the mass $m_{b}$ of the raw sand (before reaction) will be given by:

$$
m_{b}=m_{s}+m_{c}
$$

And that of the solution after reaction $\left(m_{f}\right)$ by:

$$
m_{f}=m_{s}+m_{a}+\Delta m
$$

The Equations (2), (4) and (5) provide the system of equation (6) with the unknown mass of sand $m_{s}$ that of shells $m_{c}$ and the reduction $\Delta m$.

$$
\left\{\begin{array}{l}
m_{s}+m_{c}=m_{3} \\
m_{s}+\Delta m=m_{f}-m_{a} \\
\Delta m=f\left(m_{c}\right)
\end{array}\right.
$$

The resolution of the system (6) enables to get the mass of shells $\left(m_{c}\right)$ and that of the pure sand $\left(m_{s}\right)$.

Stage 4: Calculation of the quantity of shells 
The quantity of shells $t_{c p}$ (in \%) on a sieve with mesh $\phi$, locations of samples collection in a transversal way (from Bas-E to Fin- $P A$ ) and in a longitudinal way (Profile 1 up to profile 35) is given by the Formula (7).

$$
t_{c, p}=\frac{m_{c}(\phi, p)}{m_{c, p}} \times 100
$$

The parameters of this formula are defined by:

$P$. the different zones of samples collection by profile ( $p=1$ for the Bas-E to $\mathrm{p}$ $=6$ for the Fin-PA or from profile 1 to profile 35);

$m_{c}(\phi, p)$ : the mass of shells of dimension $\phi$ for collection of samples $p$ :

$m_{c, p}$ : total mass of sand of the location of samples collection $p$.

As for quantity $t_{c, \phi}$ of shells (in \%) for mesh $\phi$ of the eight (8) sieves (0.08 $\mathrm{mm} ; 0.125 \mathrm{~mm} ; 0.25 \mathrm{~mm} ; 0.5 \mathrm{~mm} ; 1 \mathrm{~mm} ; 2 \mathrm{~mm} ; 4 \mathrm{~mm}$ and $5 \mathrm{~mm}$ ) it is given by the Formula (8).

$$
t_{c, \phi}=\frac{m_{c}(\phi, \phi)}{m_{c, \phi}} \times 100
$$

With:

$\phi:$ different sieves.

$m_{c}(\phi, \phi)$ : the mass of shells of dimension $\phi$ calculated to sieve $\phi$.

$m_{c, \phi}$ : total mass of the sand of dimension $\phi$ submitted to the test.

\section{Results}

\subsection{Law of Mass Reduction ( $\Delta m$ )}

Table 2 and Figure 3 provide the results of the destruction of shells by hydrochloric acid.

\begin{tabular}{|c|c|c|c|}
\hline $\begin{array}{l}\text { Mass of shells }(\mathrm{g}) \\
\qquad m_{\mathcal{c}}\end{array}$ & $\begin{array}{c}\text { Total mass } \\
\text { before reaction }(\mathrm{g}) \\
m_{b}=m_{c}+m_{a}\end{array}$ & $\begin{array}{c}\text { Total mass } \\
\text { after reaction }(\mathrm{g}) \text { : } \\
m_{f}\end{array}$ & $\begin{array}{c}\text { Reduction of } \\
\text { mass after reaction }(\mathrm{g}) \\
\Delta m=m_{b}-m_{a}\end{array}$ \\
\hline 0 & 40 & 40 & 0 \\
\hline 1 & 41 & 40.51 & 0.49 \\
\hline 2 & 42 & 41.13 & 0.87 \\
\hline 3 & 43 & 41.49 & 1.51 \\
\hline 4 & 44 & 42.08 & 1.92 \\
\hline 5 & 45 & 42.61 & 2.39 \\
\hline 6 & 46 & 43.02 & 2.98 \\
\hline 7 & 47 & 43.66 & 3.34 \\
\hline 8 & 48 & 44.61 & 3.39 \\
\hline 9 & 49 & 44.63 & 4.37 \\
\hline \multirow[t]{2}{*}{10} & 50 & 45.12 & 4.88 \\
\hline & \multicolumn{2}{|c|}{ Mass of hydrochloric acid $m_{a}=40 \mathrm{~g}$} & \\
\hline
\end{tabular}

Table 2. Reduction of mass $(\Delta m)$ according to quantities of initial shells $\left(m_{c}\right)$. 


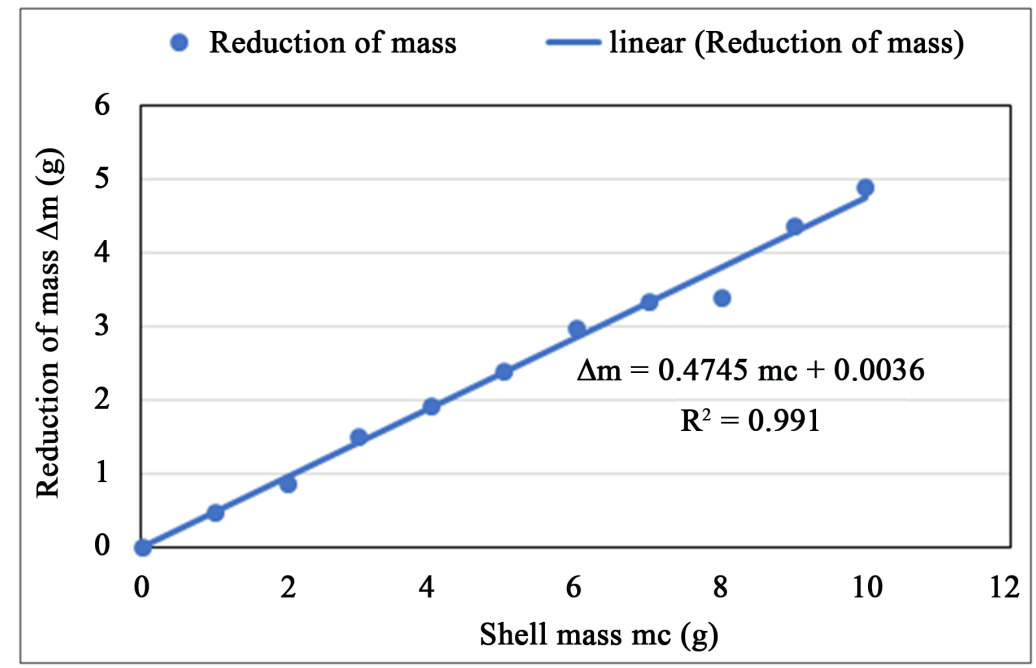

Figure 3. Evolution of the reduction of mass $(\Delta m)$ according to the mass of shells $\left(m_{c}\right)$.

The equation of smoothing that illustrates the reduction of mass $(\Delta m)$ according to the mass of shells $\left(m_{c}\right)$ has a linear form of equation (9).

$$
\Delta m=f\left(m_{c}\right)=0.475 m_{c}+0.0036 \text { avec } R^{2}=0.991
$$

To check the reliability of the developed method, two (2) series of three (3) samples of $2 \mathrm{~g}, 4 \mathrm{~g}$ and $6 \mathrm{~g}$ of raw sand of grained-size higher than $1 \mathrm{~mm}$ are submitted to two categories of tests:

- Test 1: test of destruction of shells by reaction to acid; the pure silica obtained after reaction is washed, dried in steamroom and weighed; given the mass msd:

- Test 2: test of manual siftingof shells; the sand taken out of shells by way of siftingis weighed; given the mass $m_{s t}$.

The results of these tests are recorded in Table 3 and Figure 4. Each value corresponds to the average of the two results.

The difference between the proportions of sands, the manual sifting and the destruction by acid would be due:

- Either to some possible organic impurities that acid could remove away and that the manual sifting could not allow to do;

- Either to losses of particles of grains of sands during the washing.

Considering the low value of the relative error (3.12\%), the methodology adopted allows then to have reliable quantities of shells at $96.88 \%$.

\subsection{Quantities of Shells}

From the Equations (6) and (9), the proportion of shell and that of sand are given by the Equation (10).

$$
\left[\begin{array}{ccc}
1 & 1 & 0 \\
1 & 0 & 1 \\
0 & -0.475 & 1
\end{array}\right]\left[\begin{array}{c}
m_{s} \\
m_{c} \\
\Delta m
\end{array}\right]=\left[\begin{array}{c}
m_{b} \\
m_{f}-m_{a} \\
0.0036
\end{array}\right]
$$


Table 3. Differences of mass between the destruction by acid and the manual sorting out.

\begin{tabular}{|c|c|c|c|c|c|}
\hline Echantillions & $\begin{array}{c}\text { Mass of raw sand } \\
\text { before test }(\mathrm{g}) \\
m_{b}\end{array}$ & $\begin{array}{c}\text { Mass of sand after } \\
\text { destruction by acid }(\mathrm{g}) \\
m_{s d}\end{array}$ & $\begin{array}{c}\text { Mass of sand after } \\
\text { sorting out (g) } \\
m_{s t}\end{array}$ & $\begin{array}{c}\text { Difference } \\
\text { of mass }(\mathrm{g}): \\
\Delta d=m_{s t}-m_{s d}\end{array}$ & $\begin{array}{c}\text { Relative error } \\
(\%) \\
E r r=\left(\Delta d l\left(m_{b}-m_{s d}\right)\right) \times 100\end{array}$ \\
\hline 1 & 2 & 0.72 & 0.75 & 0.03 & 2.34 \\
\hline 2 & 4 & 0.69 & 0.78 & 0.09 & 2.72 \\
\hline 3 & 6 & 1.6 & 1.79 & 0.19 & 4.32 \\
\hline \multicolumn{5}{|c|}{ Average } & 3.12 \\
\hline
\end{tabular}

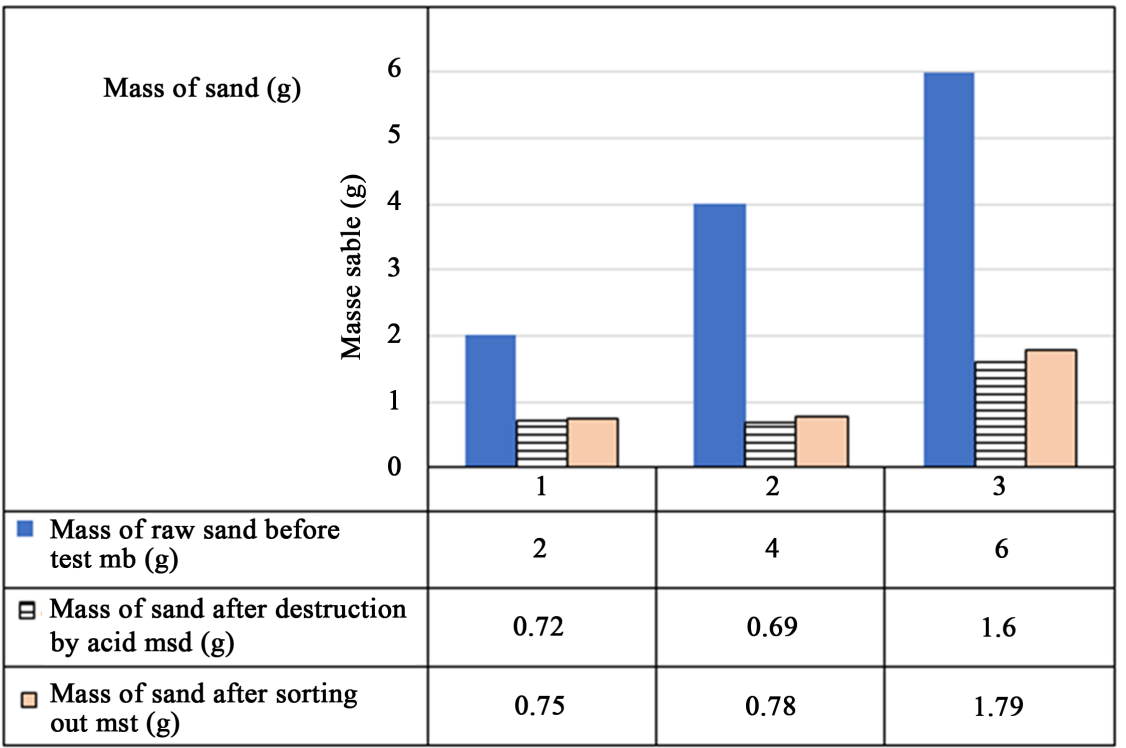

Figure 4. Graphic representation of the results of tests by manual siftingand destruction by $\mathrm{HCl}$.

From Equation (10), the mass of shells and sand is given by:

$$
\left\{\begin{array}{l}
m_{s}=\frac{1}{0.525}\left(m_{f}-m_{a}-0.475 m_{b}-0.0036\right) \\
m_{c}=\frac{1}{0.525}\left(0.0036-m_{f}+m_{a}+m_{b}-0.0036\right)
\end{array}\right.
$$

The different results of proportions of shells $\left(t_{c}\right)$ contained in the sand sediments of the littoral are given by Tables 4-6 and Figures 5-7 according to profiles and sieves. Each result is the average of values of 35 profiles or of the 6 zones of sample collection.

It can be concluded from Tables 4-6, and Figures 5-7.

- The content of shells exponentially decreases from the mesh $0.08 \mathrm{~mm}$ (tc. $\phi=$ $49.62 \%)$ at the mesh $0.5 \mathrm{~mm}\left(t_{c, \phi}=7.42 \%\right)$ and rises logarithmically then up to the mesh $4 \mathrm{~mm}$. Between the mesh $4 \mathrm{~mm}$ and $5 \mathrm{~mm}$, it is almost constant. The quantity of shells is then high $\left(t_{c, \phi} \geq 40.87 \%\right)$ in the fine-grained sands $(\phi<0.125 \mathrm{~mm})$ and in the coarse-grained $(\phi>2 \mathrm{~mm})$. This quantity is low $\left(t_{c, \phi} \leq 24.26 \%\right)$ in the sands of average-sized grain $(0.125 \mathrm{~mm} \leq \phi \leq 2 \mathrm{~mm})$ (Figure 5). 


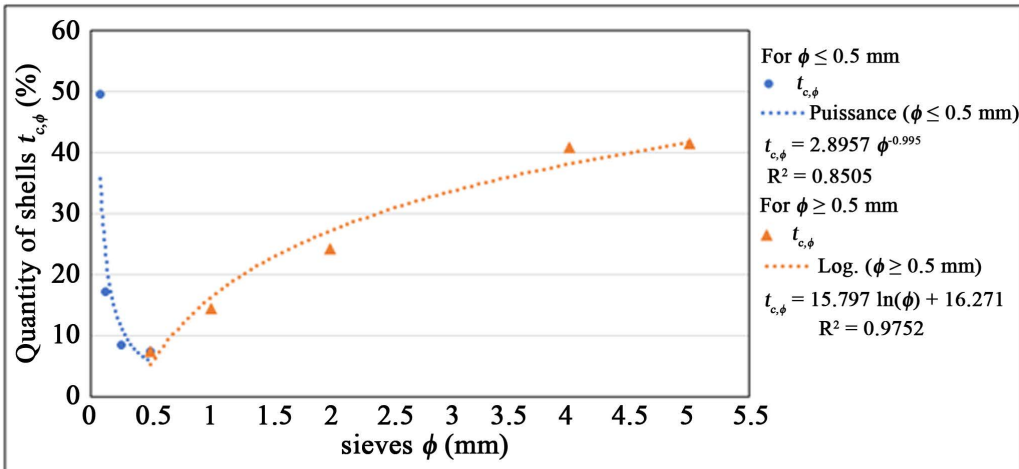

(a)

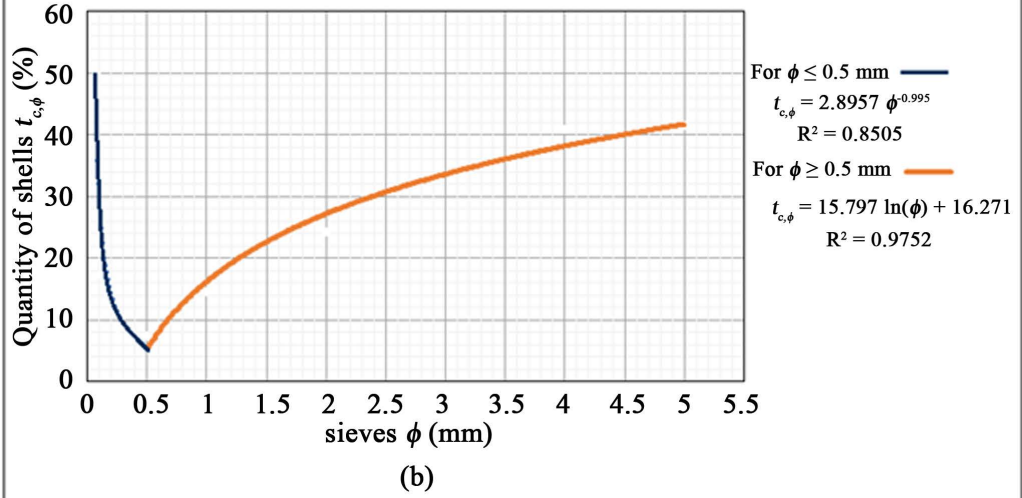

Figure 5. Distribution of the quantity of shell ( $t_{c, \phi}$ in \%) according to mesh ( $\phi$ in $\mathrm{mm}$ ). (a) Quantity of shells according to sieves; (b) Equation of distribution of the quantity of shells according to their size.

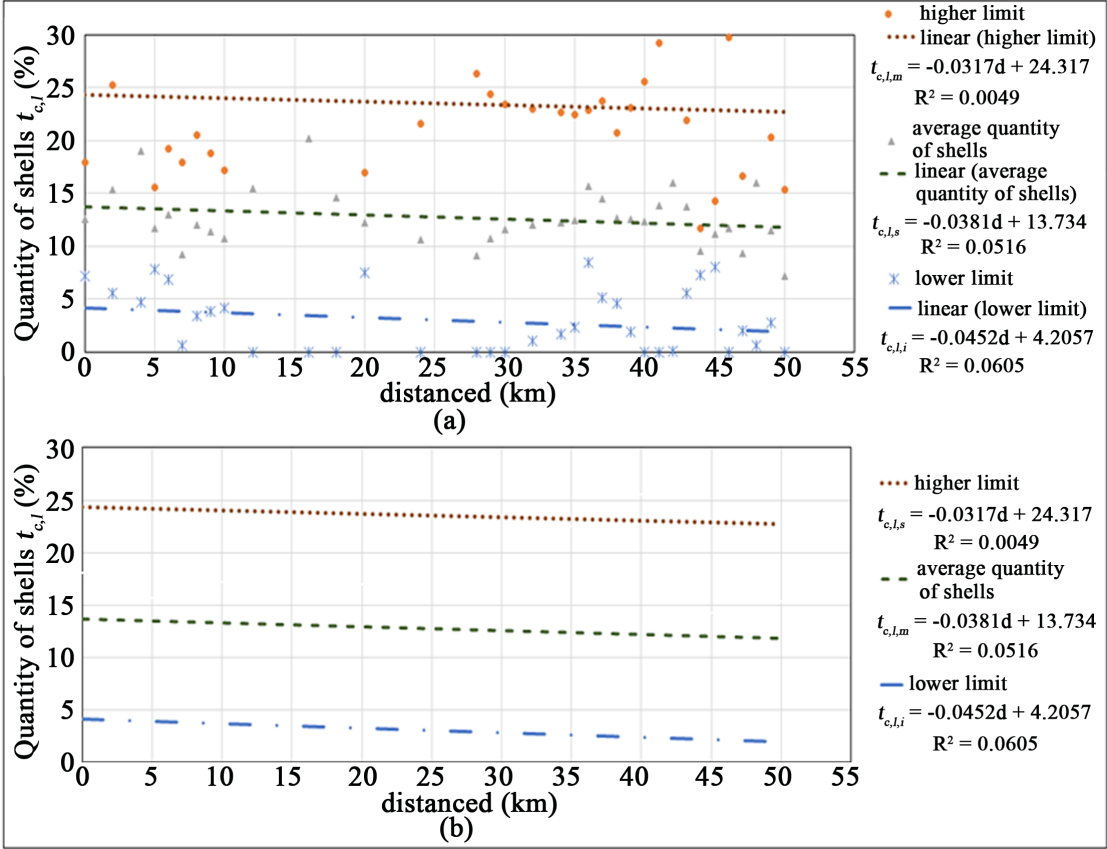

Figure 6. Qunantity of shells ( $t_{c . l}$ in \%) according to longitudinal profiles (distance $d$ in $\mathrm{km}$ ). (a) Quantity of shells according to longitudinal profiles; (b) Spindle of quantity of shells according to longitudinal profiles. 
Table 4. Quantities of shells ( $t_{c, \phi}$ in \%) according to sieves ( $\phi$ in $\mathrm{mm}$ ).

\begin{tabular}{ccccccccccc}
\hline Sieves $\phi$ in mm & & 0.08 & 0.125 & 0.250 & 0.50 & 1 & 2 & 4 & 5 \\
\hline Average quantity & $t_{c, \phi, m}$ & $(\%)$ & 49.62 & 17.23 & 8.60 & 7.42 & 14.58 & 24.26 & 40.87 & 41.55 \\
Minimum quantity & $t_{c, \phi, i}$ & $(\%)$ & $*$ & 7 & 6.13 & 3.33 & 3.81 & 5.46 & $*$ & $*$ \\
Maximum quantity & $t_{c, \phi, s}$ & $(\%)$ & 98.82 & 43.08 & 13.99 & 22.44 & 83.9 & 95.31 & 91.14 & 96.87 \\
Typical gap (\%) & 25.17 & 8.02 & 2.58 & 3.52 & 18.79 & 18.64 & 22.93 & 25.39 \\
\hline
\end{tabular}

${ }^{*}$ No refusal (sand an shell) on these meshes.

Table 5. Quantity of shells ( $t_{c, \phi}$ in \%) according to profiles (distance $d$ in $\mathrm{km}$ ).

\begin{tabular}{|c|c|c|c|c|c|}
\hline \multirow[b]{2}{*}{ Profile } & \multirow[b]{2}{*}{$\mathrm{PK}(\mathrm{km})$} & \multicolumn{3}{|c|}{ Quantity of shells $t_{c, l}(\%)$} & \multirow[b]{2}{*}{ Typical gap } \\
\hline & & $\begin{array}{c}\text { Average } \\
t_{c, l, m}\end{array}$ & $\begin{array}{c}\text { Minimum } \\
t_{c, l, i}\end{array}$ & $\begin{array}{c}\text { Maximum } \\
t_{c, l, s}\end{array}$ & \\
\hline 1 & 0 & 12.59 & 9.08 & 14.68 & 2.7 \\
\hline 2 & 2 & 15.40 & 11.13 & 22.93 & 4.93 \\
\hline 3 & 4 & 19.05 & 13.19 & 31.18 & 7.17 \\
\hline 4 & 5 & 11.71 & 8.63 & 13.88 & 1.94 \\
\hline 5 & 6 & 13.04 & 7.14 & 14.88 & 3.12 \\
\hline 6 & 7 & 9.27 & 5.65 & 15.89 & 4.31 \\
\hline 7 & 8 & 11.97 & 5.95 & 17.47 & 4.26 \\
\hline 8 & 9 & 11.32 & 5.90 & 15.91 & 3.75 \\
\hline 9 & 10 & 10.68 & 5.96 & 14.36 & 3.24 \\
\hline 10 & 12 & 15.43 & 5.03 & 28.99 & 9.22 \\
\hline 11 & 16 & 20.18 & 4.90 & 43.63 & 15.20 \\
\hline 12 & 18 & 14.61 & 8.59 & 28.22 & 7.97 \\
\hline 13 & 20 & 12.21 & 9.04 & 14.55 & 2.36 \\
\hline 14 & 24 & 10.65 & 4.87 & 18.45 & 5.49 \\
\hline 15 & 28 & 9.08 & 0.70 & 22.35 & 8.63 \\
\hline 16 & 29 & 10.74 & 3.89 & 20.61 & 6.83 \\
\hline 17 & 30 & 11.57 & 5.49 & 19.74 & 5.93 \\
\hline 18 & 32 & 11.99 & 6.29 & 19.31 & 5.48 \\
\hline 19 & 34 & 12.2 & 6.69 & 19.09 & 5.26 \\
\hline 20 & 35 & 12.4 & 7.09 & 18.88 & 5.04 \\
\hline 21 & 36 & 15.64 & 10.19 & 19.91 & 3.60 \\
\hline 22 & 37 & 14.47 & 9.12 & 21.80 & 4.66 \\
\hline 23 & 38 & 12.65 & 8.99 & 18.88 & 4.05 \\
\hline 24 & 39 & 12.52 & 7.21 & 20.88 & 5.31 \\
\hline 25 & 40 & 12.38 & 5.43 & 22.89 & 6.58 \\
\hline 26 & 41 & 13.81 & 8.36 & 27.35 & 7.73 \\
\hline 27 & 42 & 15.97 & 6.92 & 27.96 & 7.94 \\
\hline 28 & 43 & 13.76 & 10.49 & 20.44 & 4.09 \\
\hline 29 & 44 & 9.5 & 7.77 & 10.76 & 1.10 \\
\hline 30 & 45 & 11.14 & 6.58 & 10.00 & 1.55 \\
\hline
\end{tabular}




\section{Continued}

\begin{tabular}{cccccc}
\hline 31 & 46 & 11.65 & 6.06 & 27.65 & 9.05 \\
32 & 47 & 9.34 & 4.08 & 11.62 & 3.67 \\
33 & 48 & 15.98 & 9.17 & 28.50 & 7.68 \\
34 & 49 & 11.53 & 5.51 & 17.54 & 4.37 \\
35 & 50 & 7.18 & 4.31 & 14.27 & 4.09 \\
Average & 48 & 12.67 & & & \\
Minima & 49 & & 0.70 & & \\
Maxima & 50 & & & 43.63 &
\end{tabular}

Table 6. Proportion of shells according to zones of samples collection.

\begin{tabular}{ccccccc}
\hline Zones of samples collection & $\begin{array}{c}\text { Fin-PA } \\
(1)\end{array}$ & $\begin{array}{c}\text { Mi-PA } \\
(2)\end{array}$ & $\begin{array}{c}\text { Début-PA } \\
(3)\end{array}$ & $\begin{array}{c}\text { Haut-E } \\
(4)\end{array}$ & $\begin{array}{c}\text { Mi-E } \\
(5)\end{array}$ & $\begin{array}{c}\text { Bas-E } \\
(6)\end{array}$ \\
\hline Average quantity $t_{c, l, m}(\%)$ & 12.47 & 14.20 & 13.75 & 13.29 & 11.80 & 13.32 \\
Minimum quantity $t_{c, l, i}(\%)$ & 2.06 & 0.70 & 3.50 & 6.30 & 6.25 & 5.65 \\
Maximum quantity $t_{c, l, s}(\%)$ & 31.18 & 25.36 & 38.50 & 52.21 & 43.63 & 22.35 \\
Typical gap (\%) & 6.80 & 5.13 & 7.12 & 9.09 & 7.91 & 3.89 \\
\hline
\end{tabular}

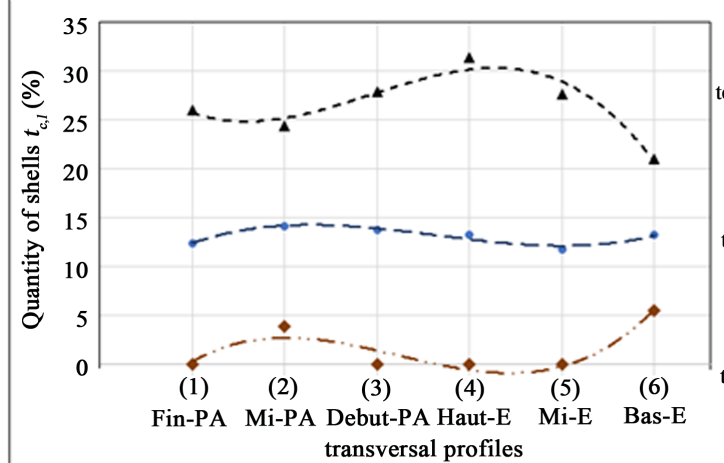

(a)

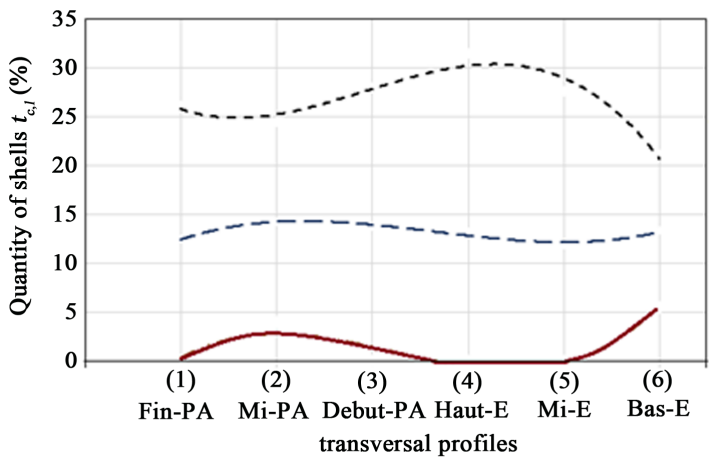

- - - higher limit tcti $=0.5119 \mathrm{x}^{3}-4.9502 \mathrm{x}^{2}+13.709 \mathrm{x}-8.9467$ - - average quantity of shells tcts $=-0.5638 \mathrm{x}^{3}+4.9543 \mathrm{x}^{2}-11.453 \mathrm{x}+32.837$

- - cuve of lower limit cti $=0.5119 x^{3}-4.9502 x^{2}+13.709 x-8.9467$ $R^{2}=0.874$

- higher limit cts $=-0.5638 \mathrm{x}^{3}+4.9543 \mathrm{x}^{2}-11.453 \mathrm{x}+32.837$

- average quantity of shells

-- cuve of average quantity

$\mathrm{ctm}=0.2119 \mathrm{x}^{3}-2.3185 \mathrm{x}^{2}+7.2725 \mathrm{x}+7.27$ $\mathrm{R}^{2}=0.8959$

$\mathrm{R}^{2}=0.931$

- lower limit

For $\mathrm{x}<4$ et $\mathrm{x}>5$

$\mathrm{tctm}=0.2119 \mathrm{x}^{3}-2.3185 \mathrm{x}^{2}+7.2725 \mathrm{x}+7.27$

$\mathrm{R}^{2}=0.8959$

tctm $=0$

(b)

Figure 7. Variation of quantities of shells ( $t_{c . l}$ in \%) according to zones of samples collection. (a) Quantity of shells according to transversal profiles; (b) Spindles of quantity of shells according to transversal profiles. 
The equations of smoothing that illustrate the variations of the quantities of shells in the Togolese sediments according to their size are given by:

for $\phi \leq 0.5$

$$
t_{c, \phi}(\phi)=2.8957 \phi^{-0.995} \text { avec } R^{2}=0.8505
$$

for $\phi \geq 0.5$

$$
t_{c, \phi}(\phi)=15.797 \ln (\phi)+16271 \text { avec } R^{2}=0.9752
$$

In these equations, $t_{c, \phi}(\phi)$ is the quantities of shell (in \%) and $\phi$ the meshes of sieves (in $\mathrm{mm}$ ).

- The quantity of shells generally decreases in a linear way from the profile 1 up to profile 35 corresponding to the direction of the sediments' transportations (Figure 6). The equations of smoothing that illustrate this behavior of the quantities of shells in the Togolese sediments are given by: for the higher limit:

$$
t_{c, l, s}(d)=-0.0317 d+24.317 \text { avec } R^{2}=0.0049
$$

for the average quantity:

$$
t_{c, l, m}(d)=-0.0381 d+13.734 \text { avec } R^{2}=0.0516
$$

for the lower limit:

$$
t_{c, l, i}(d)=-0.0452 d+4.206 \text { avec } R^{2}=0.0605
$$

With $t_{c, l}(d)$, the quantities of shells (\%) and $d$, the distance of longitudinal profiles (in km).

- The content of shells rises from the end of aerial beach (Fin-PA) up to the aerial mid-beach (Mi-PA), and then decreases up to the mid-foreshore (Mi-E) and ends up with another increase up to the low-foreshore (Bas-E) (Figure 7).

The behavior of the quantities of shells in the Togolese sediments is illustrated by the equations given by:

For the higher limit:

$$
t_{c, t, s}(x)=0.5638 x^{3}-4.9543 x^{2}+11.453 x+32.837 \text { avec } R^{2}=0.9311
$$

For the average quantities:

$$
t_{c, t, m}(x)=0.2119 x^{3}-2.3185 x^{2}+0.2725 x+7.27 \text { avec } R^{2}=0.8959
$$

For the lower limit:

$$
t_{c, t, i}(x)=0.5119 x^{3}-4.9502 x^{2}+13.709 x+8.9467 \text { avec } R^{2}=0.874
$$

In these equations, $t_{c, t}(x)$ is the quantity of shells (in \%) and $x$ the transversal profiles ( $x=1$ for Fin-PA to $x=6$ for Bas-E).

\section{Discussion}

From this study we can conclude that the content of shells is high ( $\left.t_{c, \phi}=49.62 \%\right)$ in the fine-grained sands (mesh $\phi<0.125 \mathrm{~mm}$ ) implying that some shells from the sands of Togolese littoral are fine-grained or they are fragile. This is for instance the case for the shells of shellfishes and seiches. These shells, under the influence of the sedimentary transportation, break up into fine grains. Also, 
there exist shells with the grain size higher than $2 \mathrm{~mm}$ for a high quantity $\left(t_{c, \phi} \geq 40.87 \%\right)$. This presence of shells of coarse size would be due to the existence of coarse-grained shells or not fragile and that practically don't undergo any break during their transportation. This is for instance the case for shells of the arca senelis and the oliva flammulata. Their high quantity of shells in the fine sands $(\phi<0.125 \mathrm{~mm})$ and coarse-grained sands $(\phi>2 \mathrm{~mm})$ is due to the scarcity of the grains of sand lower than $0.125 \mathrm{~mm}$ and higher than $4 \mathrm{~mm}$ in the sea sediments. In fact, the sand sediments of Togolese littoral practically don't contain grains lower than $0.125 \mathrm{~mm}$ and higher than $4 \mathrm{~mm}$ (respective proportions $0.46 \%$ and $0.25 \%$ ) [12] [13] [14] [15] [16].

The quantity of shells generally declines following the direction of the littoral drift. But the very low coefficient of regression $\left(\mathrm{R}^{2}<0.1\right)$ implies the genuine absence of link between the quantity of shells and the direction of the sedimentary transportation. This behavior can be explained by the distribution of the life of animals in the sea all along of the guinea gulf that is reflected in the presence of shells of various nature [4].

With the exception of the location Fin-PA, the quantity of shells is lower and lower from the aerial mid-beach (Mi-PA) $\left(t_{c . t}=14.20 \%\right)$ to the mid-foreshore $(\mathrm{Mi}-\mathrm{E})\left(t_{c . t}=11.80 \%\right)$ and higher and higher from mid-foreshore $(\mathrm{Mi}-\mathrm{E})\left(t_{c . t}=\right.$ $11.80 \%)$ to low-foreshore (Bas-E) $\left(t_{c . t}=13.32 \%\right)$. This quantity is low at the end of aerial beach (Fin-PA) $\left(t_{c . t}=12.47 \%\right)$. The low quantity on the aerial beach can be due to the presence in the sand sediments of the sands of the dune that mostly contain no shells. As for the presence of shells in the mid-beach. As for the presence of shells in the mid-beach and aerial low, it would probably due to the sweeping of fine elements of sand sediments by the wind exposing then the shells. The high quantity of shells on the low-foreshore is conforming to the transversal differential distribution of sand grains that are average-sized grains $(1,2$ and $4 \mathrm{~mm})$ that represent increasing proportions from high-foreshore to low-foreshore [12]. This behavior would be caused by their transportation by carriage owing to the significant energy of waves that deposit them on the low-foreshore that represent the end of the breaking zone where waves break and lose a great part of their energy. Thus, the transportation capability of coarse particles (sands and shells) toward the mid-foreshore gets reduced.

The average quantity of shells provided by the average of the quantities of 210 samples accounts for $12.67 \%$ for a maximal quantity of $20.18 \%$ and a minimal quantity of $7.18 \%$ (Table 7 ). The typical gap is $12.67 \%$. These quantities of sand

Table 7. Average amount of shells in the sand of the Togolese coast.

\begin{tabular}{cc}
\hline Parameters & Shells quantity \\
\hline Average quantity (\%) & 12.67 \\
Minimal quantity (\%) & 7.18 \\
Maximal quantity (\%) & 20.18 \\
Typical gap (\%) & 2.71 \\
\hline
\end{tabular}


shells are lower than the recommended $30 \%$ by the standard NF EN 933-7 [17] and N EN 12620 [1].

\section{Conclusion}

This study showed that the quantity of shells in the sea sediments of the Togolese littoral gets lower and lower from the aerial mid-beach to mid-foreshore, and gets higher and higher from the mid-foreshore to the low-foreshore. The quantity of shells is generally high in the fine-grained sands and in the coarse-grained sands, and low in the average-sized sands. The quantity of shells of $12.67 \%$ is lower than the recommended maximal quantity (30\%) for sands used in concrete. For concrete works, the sands from littorals contain quantities of shells that are not detrimental (quantity lower than 30\%) to their usage as granulate for concrete.

\section{Acknowledgements}

This work could be done without formal logistic and financial support from FORMATEC we express our sincere gratitude to.

\section{Conflicts of Interest}

The author declares no conflicts of interest regarding the publication of this paper.

\section{References}

[1] NF EN 12620 (2002) Granulats pour béton.

[2] Amey, K.B., Neglo, K., Tamba, S., Johnson, A.K.C., Kouto, Y. and Nayo, E. (2014) Caractérisation physique de sables silteux au Togo. Afrique SCIENCE, 10, 53-69. https://www.ajol.info/index.php/afsci/article/view/109653

[3] Amey, K.B. and Neglo, K. (2018) Characterisations of Parameters of Granularity of Sediments from Togolese Littoral: Granular Potential. American Journal of Applied Sciences, 15, 399-408. http://thescipub.com/abstract/10.3844/ofsp.12132 https://doi.org/10.3844/ajassp.2018.399.408

[4] Projet Mangroves (1990) Etude des zones inondées au Togo: Végétation, faune et écologie des mangroves. Rapport final, Université de Lomé, Faculté des Sciences, laboratoire de botanique-Laboratoire de zoologie, Lomé, Togo.

[5] NF EN 933-1 (1997) Essais pour déterminer les caractéristiques géométriques des granulats, Partie 1: Détermination de la granularité-Analyse granulométrique par tamisage.

[6] NF EN 933-2 (1996) Essais pour déterminer les caractéristiques géométriques des granulats, Partie 2: Détermination de la granularité-Tamis de contrôle, dimensions nominales des ouvertures.

[7] NF ISO 9276-2 (2001) Représentation de données obtenues par analyse granulométrique-Partie 2: Calcul des tailles/diamètres moyens des particules et de moments à partir de distributions granulométriques.

[8] NF ISO 9276-4 (2001) Représentation de données obtenues par analyse granulométrique-Partie 4: Caractéristique d'un processus de triage. 
[9] NF ISO 9276-1 (1998) Représentation de données obtenues par analyse granulométrique-Partie 1: Représentation graphique.

[10] NF P 18-304 (1973) Granulométrie des granulats.

[11] NF X 11-630 (2001) Granulométrie-Vocabulaire.

[12] Amey, K.B., Bedja, K. and Neglo, K. (2004) Distribution longitudinale de la granulométrie du sable littoral togolais: Grain moyen, sorting index et skewness. Journal des Sciences Pour Ingénieur, No. 8, 1-8. https://doi.org/10.4314/jspi.v8i1.30043

[13] Amey, K.B. (2006) Caractérisation des sédiments sableux du littoral togolais: expérimentation et détermination d'une formule de sable normal. Thèse de Doctorat unique en Sciences de l'Ingénieur à l'Université de Lomé au Togo.

[14] Amey, K.B., Bedja, K. and Neglo, K. (2013) Etude de l'évolution transversale des distributions différentielle et cumulative et de la classe granulaire des granulats marins du littoral togolais. Journal de la Recherche Scientifique de P Université de Lomé, 7, 13-20. https://www.ajol.info/index.php/jrsul/article/view/119075

[15] Amey, K.B., Samah, O.D., Neglo, K., Amoussou, K., Sounsah, K.M. and Tchamdja, B. (2018) Experimental Study of the Formulation of Mortar Based on Silty Sand of Togo. American Journal of Civil Engineering and Architecture, 6, 172-179. http://pubs.sciepub.com/ajcea/6/5/1

[16] Amey, K.B. (2018) Formulation de la composition de mortier: expérimentation faite sur les sables silteux. Editions Universitaires Européennes, OmniScriptum Publishing Group, Germany.

[17] NF EN 933-7 (1998) Essais pour déterminer les caractéristiques géométriques des granulats, Partie 7: Détermination de la teneur en coquille-Pourcentage de coquilles dans les gravillons. 